\title{
Bearing capacity of steel thin-walled profiles in reliability assessment
}

\author{
Natalia Korsun* and Daria Prostakishina \\ Industrial University of Tyumen, Department of Building structures, 625000 Volodarsky str., 38, \\ Tyumen, Russia
}

\begin{abstract}
The increasing use of light steel thin-walled structures is determined by the efficiency of the production of cold-formed profiles. However, there are problems of calculating the reliability of thin-walled structures. In particular, it is necessary to specify the calculation of the generalized bearing capacity of an element from a thin-walled profile. Such an element is significantly affected by the initial geometric imperfections reducing its bearing capacity. At the same time the element is influenced by an uneven distribution of the mechanical characteristics of the steel over the section of the profile. A thin-walled element of paired sigma profiles with a section height of $300 \mathrm{~mm}$ was taken as the object of study. This paper presents the results of the calculation of the effective characteristics of a thin-walled profile operating under axial compression with bending without and with the initial geometric imperfections (additional eccentricity from the element's initial curvatures). Besides, the paper reveals the results of laboratory studies of the distribution of the mechanical properties of steel over the cross section of a thin-walled profile after using direct and indirect test methods.
\end{abstract}

\section{Introduction}

The demand for a correct assessment of the reliability of building structures and the use of effective design solutions is justified by a number of reasons. The main of them is to ensure the bearing capacity and reduce the risk of failure of structures. However, this factor is directly related to high safety margins, which are often economically disadvantageous.

Light steel thin-walled structures (CFS) are structures manufactured from cold-rolled thin-sheet $(0.6 \div 3 \mathrm{~mm})$ steel by cold bending on rolling mills with subsequent galvanizing. CFS construction is the most industrialized and easily managed process, as it includes fully prefabricated construction. The structures erected from CFS are light skeletons, the frames of which are interconnected into a spatial system. Paired profiles are most frequently used as the main bearing elements of the frame of CFS. The paired profiles are interconnected in a symmetrical section with bolts, self-tapping screws, and rivets.

The criteria affecting the generalized bearing capacity of the elements are the geometric characteristics of their cross sections and the mechanical properties of the material. The features of the elements of CFS, affecting the generalized bearing capacity are the initial geometric imperfections of the elements, as well as the uneven distribution of the

*Corresponding author: korsunnd@tyuiu.ru 
mechanical properties of the material over the cross section of the profile $[1,2,3,4,5,6$, 7].

Geometric imperfections arise due to elastic and elastoplastic deformations in profile manufacturing by cold rolling. Accounting for initial geometric imperfections is characterized by an increase in stresses due to the occurrence of additional eccentricities from initial curvatures $[8,9,10,11,12,13,14]$.

The uneven distribution of the mechanical characteristics of the material over the cross section of the cold-formed profile is due to the formation of work hardening zones in places of bending. There are several studies of the distribution of mechanical characteristics over the cross section of a cold-formed profile [15, 16, 17, 18, 19], according to which the hardening of steel directly along the bending line reaches $40-60 \%$, and the hardening of steel in sections $(3 \div 6) \mathrm{t}$ adjacent to the bent zone (here $\mathrm{t}$ is the sheet thickness) reaches 15 $25 \%$. The code of design rules for thin-walled structures SP 260.1325800.2016 is based on the European standard EN 1993-1-3: 2006 [20]. This code regulates the determination of the regulatory and design resistances of steel based on the statistical processing of experimental data using the minimum distribution values. While calculating, it is allowed to take into account the variability of the mechanical properties of steel over the cross section of the curved profile. This significantly increases the theoretical load-bearing capacity of the thin-walled cold-formed profile element by increasing the design steel resistance of section stiffness elements, thus affecting the geometric characteristics of the effective section and its stability.

But until now there are no generally accepted approaches to accounting for these factors when assessing the bearing capacity of thin-walled cold-formed elements.

\section{Material and methods}

The choice of the object of study and its design scheme is determined by the work of columns and girders composing frames from CFS. They are the elements influenced by a longitudinal compressive force and bending moment in the plane of the transverse frame and braced from the plane.

An element of two paired sigma profiles with a section height of $300 \mathrm{~mm}$ from a 2.5 mm thick sheet was taken as an object of study (Fig. 1). The length of the element is $\mathrm{L}=$ $15 \mathrm{~h}=4500 \mathrm{~mm}$. Material is steel 350 according to GOST R 52246-2016 "Hot-galvanized sheet metal. Technical conditions" (Table 1). The design scheme of the element is shown in Fig.2. Fastening in the plane of the bending moment is made hinged at the ends of the element, and $1500 \mathrm{~mm}$ from the plane of the bending moment.
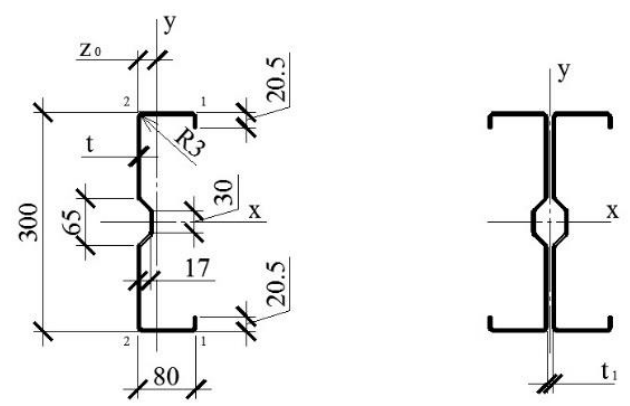

Fig.1. Geometrical dimensions of the sigma profile and the shape of the paired section 
Table 1. Mechanical properties of steel sheets in accordance with GOST R 52246-2016

\begin{tabular}{|c|c|c|c|}
\hline Mill product brand & $\begin{array}{c}\text { Tensile strength } \\
\boldsymbol{\sigma}_{\mathbf{u}}, \mathbf{N} / \mathbf{m m}^{2}\end{array}$ & $\begin{array}{c}\text { Yield point } \\
\boldsymbol{\sigma}_{\mathbf{0 . 2}}, \mathbf{N} / \mathbf{m m}^{2}\end{array}$ & $\begin{array}{c}\text { Relative elongation } \\
\mathbf{\delta}, \boldsymbol{\%}, \text { for } \mathbf{2 . 5} \mathbf{~ m m} \\
\text { thick steel }\end{array}$ \\
\hline 350 & Not less than 420 & Not less than 350 & Not less than 16 \\
\hline
\end{tabular}

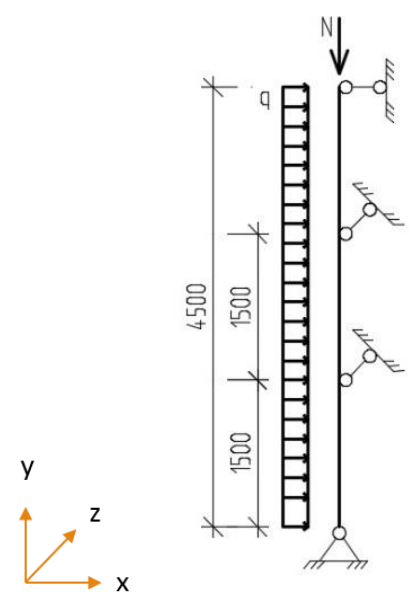

Fig. 2. The design scheme of the object of study

Local geometrical imperfections of the profiles are specified according to SP 260.1325800.2016. General imperfections are specified according to GOST 23188-2012. This value is $30 \mathrm{~mm}$ for elements of the fifth accuracy class and $4.5 \mathrm{~m}$ of length.

In the course of analysis there were made calculations of the effective characteristics of a thin-walled profile operating under axial compression with bending (eccentric compression) without and with its initial geometric imperfections taken into account.

Initial imperfections were specified by applying a longitudinal load with an additional eccentricity about the bar axis, corresponding to the magnitude of the geometric imperfections. During the study, two characteristic cases of application of longitudinal compressive force were identified:

Case 1 - the displacement of the longitudinal force in the plane of the bending moment by $30 \mathrm{~mm}$ without angular displacement;

Case 2 - the displacement of the longitudinal force in the plane perpendicular to the plane of the bending moment, with an angular displacement of \pm 45 degrees.

To determine the distribution of mechanical properties of steel over the profile section, the authors used two groups of methods:

- indirect methods, which consist in determining the mechanical properties of steel by measuring the Brinell hardness (Fig.3);

- direct tensile test methods on an I1147M-50-01-1 tensile testing machine (Fig.4). 

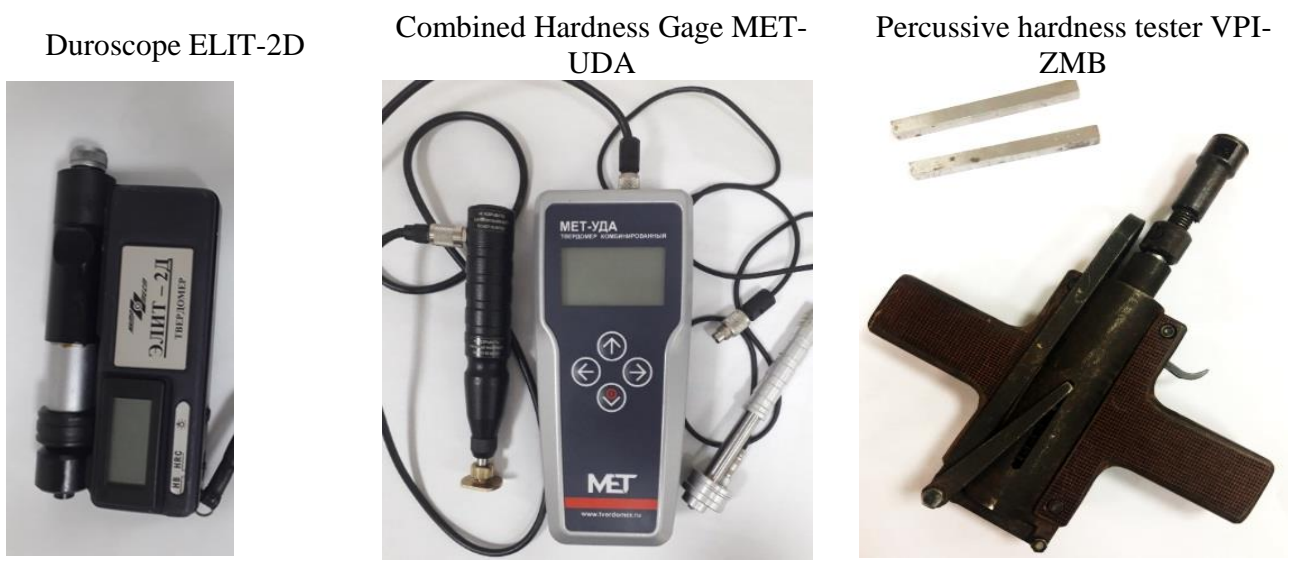

Fig. 3. Devices for determining the mechanical properties of steel by the methods of hardness testing
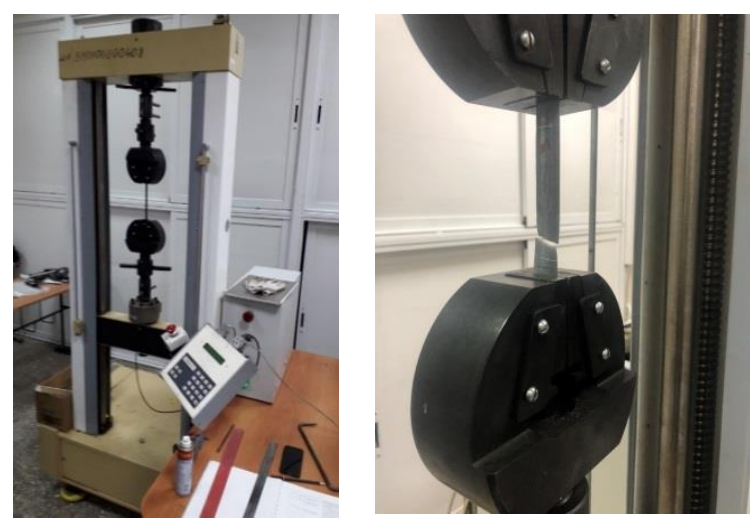

Fig. 4. Steel samples tensile testing

Based on the results obtained by other researchers, six characteristic zones have been distinguished in the cross section of the sigma profile (Fig.5): zones 1 and 2 are the bend points at right and obtuse angles, zones 3 and 5 are the sections adjacent to the bend points, zones 4 and 6 - straight sections.

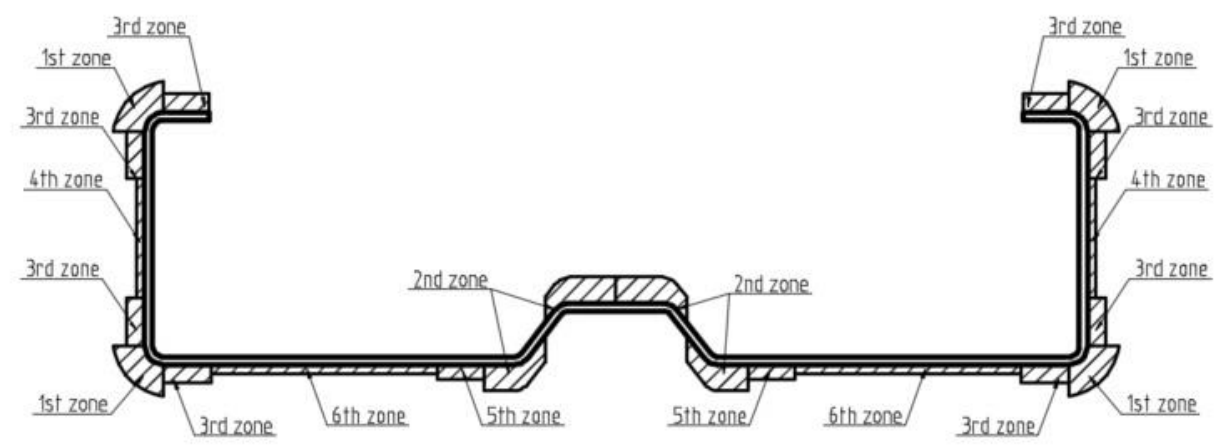

Fig. 5. Characteristic zones of the section to account for the mechanical properties of the material 
According to the developed program, tests are carried out on whole fragments of a sigma profile with an external surface pre-cleaned of zinc coating and filled with heavy concrete (Fig.6) and on steel strips 15-30 mm wide, 180-220 mm long, cut from fragments of the sigma profile along the rolled products (Fig. 7).
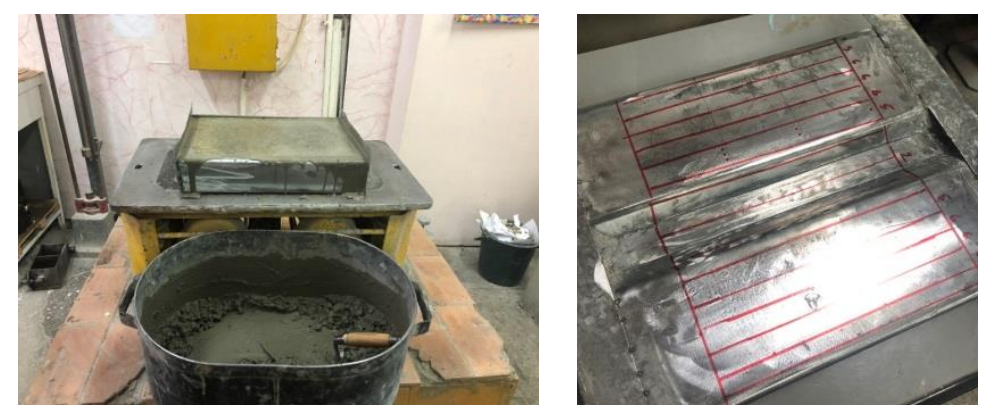

Fig. 6. Sample from the whole piece of sigma profile filled with heavy concrete
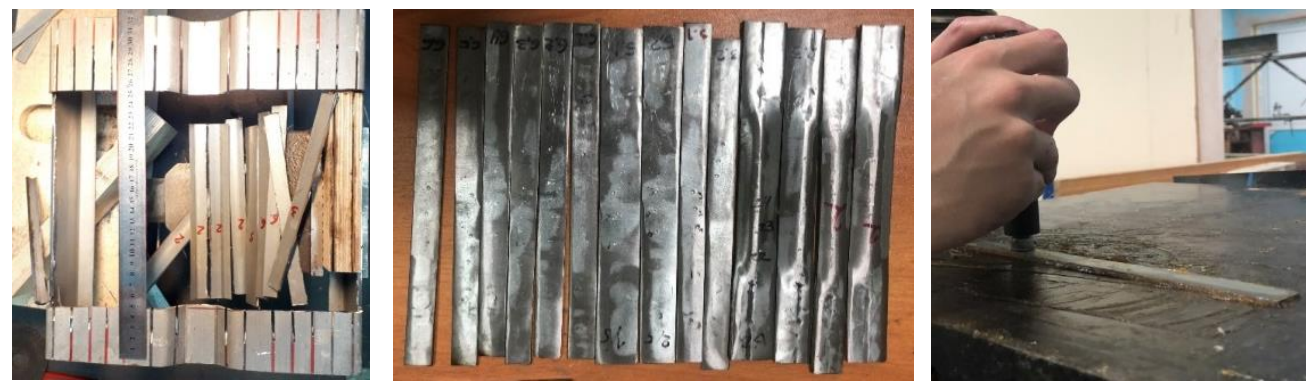

Fig. 7. Sample strips for testing steel thin-walled bent profile

\section{Results}

The calculation of the effective geometric characteristics of the section showed (Table 2) a significant effect of the initial geometric imperfections, a reduction of the cross section area occurs by 16 and $25 \%$ respectively for cases 1 and 2 in comparison with the case that does not take into account the initial geometric imperfections.

Table 2. Geometric characteristics of the effective cross section under eccentric compression

\begin{tabular}{|c|c|c|c|}
\hline & \multirow{2}{*}{$\begin{array}{c}\text { Initial } \\
\text { imperfections not } \\
\text { taken into account }\end{array}$} & \multicolumn{2}{|c|}{$\begin{array}{c}\text { Initial imperfections taken into } \\
\text { account }\end{array}$} \\
\cline { 3 - 4 } & 11.63 & 9.74 & Case 1 \\
\hline$A_{\text {red }}, \mathrm{cm}^{2}$ & 0.58 & 0.49 & 8.75 \\
\hline$A_{\text {red }} / A$ & & & 0.44 \\
\hline
\end{tabular}

The increase in stresses occurs due to the loss of local stability of individual elements of the cross section, and the elastoplastic work of the material occurs when the stresses in the total cross section are equal to $0.71 \mathrm{R}_{\mathrm{y}}$. When the initial imperfections are taken into account, the material transforms into the zone of elastoplastic work at stresses in full 
section equal to $0.58 \mathrm{R}_{\mathrm{y}}$. The increase in stresses is associated with the occurrence of additional efforts $\Delta \mathrm{M}_{\mathrm{x}}$ and $\Delta \mathrm{M}_{\mathrm{y}}$.

At this stage of studying the uneven distribution of the mechanical properties of the material over the cross section of the profile, the obtained results were statistically processed for the characteristic zones No. 1, No. 3, No. 6 (Fig. 5).

The surface hardness values of samples of zone No. 1 vary within $\mathrm{HB}=195-228$ for a single sample, $\mathrm{HB}=136-217$ for plate samples, zone No. $3 \mathrm{HB}=182-200$ for the whole sample, HB = 116-181 for plate samples, zone No. $6 \mathrm{HB}=175-199$ for the whole sample, $\mathrm{HB}=153-181$ for plate samples. The main numerical parameters of the surface hardness distribution functions over the cross section zones are given in Tables 3, 4 .

Table 3. Numerical parameters of the hardness distribution functions on the surface of the zones of the whole sample

\begin{tabular}{|c|c|c|}
\hline No of a zone & Expected value $\mathbf{~ m}$ & Standard deviation $\boldsymbol{\sigma}$ \\
\hline 1 & 211.5 & 9.7 \\
\hline 3 & 193.01 & 4.17 \\
\hline 6 & 192.3 & 11.2 \\
\hline
\end{tabular}

Table 4. Numerical parameters of the hardness distribution functions on the surface of the zones of plate sample

\begin{tabular}{|c|c|c|}
\hline No of a zone & Expected value $\mathbf{m}$ & Standard deviation $\boldsymbol{\sigma}$ \\
\hline 1 & 172.9 & 26.8 \\
\hline 3 & 157.4 & 20.8 \\
\hline 6 & 172.2 & 6.4 \\
\hline
\end{tabular}

The values of yield strength and temporary resistance vary within $\sigma_{0.2}=470-525 \mathrm{MPa}$, $\sigma_{\mathrm{u}}=500-540 \mathrm{MPa}$ for zone No. 1, $\sigma_{0.2}=420-475 \mathrm{MPa}, \sigma_{\mathrm{u}}=460-500 \mathrm{MPa}$ for zone No. 3, $\sigma_{0.2}=370-420 \mathrm{MPa}, \sigma_{\mathrm{u}}=440-510 \mathrm{MPa}$ for zone No. 6 . The main numerical parameters of the distribution functions of the values of the yield strength and temporal resistance of the samples are given in Tables 5, 6.

Table 5. The numerical parameters of the distribution functions of the values of the yield strength of samples

\begin{tabular}{|c|c|c|}
\hline No of a zone & Expected value $\mathbf{~}$ & Standard deviation $\boldsymbol{\sigma}$ \\
\hline 1 & 494.8 & 12.4 \\
\hline 3 & 438.7 & 15.4 \\
\hline 6 & 395.8 & 14.3 \\
\hline
\end{tabular}


Table 6. The numerical parameters of the distribution functions of the values of the temporal resistance of samples

\begin{tabular}{|c|c|c|}
\hline No of a zone & Expected value $\mathbf{~}$ & Standard deviation $\boldsymbol{\sigma}$ \\
\hline 1 & 518.0 & 10.1 \\
\hline 3 & 470.4 & 9.3 \\
\hline 6 & 466.4 & 14.5 \\
\hline
\end{tabular}

\section{Discussions and conclusions}

Analytical calculations revealed a significant effect of initial geometric imperfections. Depending on the location of the additional eccentricity, the reduced element crosssectional area is reduced by $16-26 \%$. The most unfavorable is the displacement of the longitudinal force in the plane perpendicular to the plane of action of the bending moment, with an angular displacement of \pm 45 degrees. In this case, the increase in stresses in the cross section of an eccentrically compressed element was $18 \%$.

The results of tensile testing of a batch of 75 samples of zones No. 1, 3 and 6 confirmed the hardening of steel. In places of bending (zone No. 1) the increase in the minimum value of temporary resistance was $19 \%$, the offset yield strength of $34 \%$. In the areas adjacent to the bending zones (zone No. 3), the increase in the minimum value of the temporary resistance was $10 \%$, and the offset yield strength of $20 \%$. Increments in the minimum values of the mechanical properties of steel in straight sections (zone No. 6) are insignificant.

While testing tensile and determining the surface hardness of thin-walled specimens, the researchers revealed the necessity of adapting the standard test methods.

In the practical use of hardness testers, the following problems arose:

- when measuring the hardness with an ELIT-2D duroscope, as well as with a dynamic sensor of a combined MET-UDA device, thin-walled samples must be rubbed through a layer of grease to a more massive support, and curvilinear samples must fit tightly against it, which is time-consuming;

- as for hardness testers of plastic deformation, conducting large-scale tests is limited by the number of reference samples, as well as factors related to the safety of work;

- the ultrasonic nozzle of the MET-UDA hardness tester gives a large scatter of results and requires high precision of applying the nozzle to the surface in two stages with a certain effort and exclusively at a right angle.

As a result, the dynamic duroscope ELIT-2D proved to be the most appropriate from the instruments used for determining the hardness of thin-walled metal.

When preparing plate type samples from a curved profile, it turned out to be difficult to cut them, since plasma and laser metal cutting machines are designed to work only with sheet metal. To test the bending line specimens requires the preparation of the ends of the specimen for fastening in the grippers of a tensile machine.

The obtained test results confirm the presence of metal hardening zones in places of bending, which allows using additional reserves of metal for the compressed zone of the section.

Further studies of the generalized bearing capacity of steel thin-walled profiles should focus on the development of plastic strain in the compressed zone of the cross section, taking into account the hardening of the material along the bending lines. 


\section{References}

1. E. L. Airumyan, StroyProfil 10, 12-17 (2013)

2. E. L. Airumyan, StroyProfil 8, 12-14 (2009)

3. E. L. Airumyan, StroyProfil 3, 2-7 (2008)

4. G. I. Beliy, Vestnik grajdanskih injenerov 32, 99-103 (2012)

5. G. I. Beliy, Vestnik grajdanskih injenerov 61, 75-80 (2017)

6. G. I. Beliy, Vestnik grajdanskih injenerov 64, 33-37 (2017)

7. A. A. Kikot, V.V. Grigoriev, Inejerno-stroitelny jurnal 1, 97-101 (2013)

8. B. W. Schafer, Journal of Constructional Steel Research 64, 766-778 (2008)

9. B. W. Schafer, Journal of Constructional Steel Research 47, 193-210 (1998)

10. J. Rondal, D. Duubina, V. Ungureanu, Steel Compos Struct, 2005

11. Bong Kwon Young, Sun Kim Bong, Gregory J. Hancock, Journal of Constructional Steel Research 65, 278-289 (2009)

12. Krishanu Roy, Tina Chui Huon Ting, Hieng Ho Lau, James B.P. Lim, Journal of Constructional Steel Research 174, 257-276 (2018)

13. G.G. Kashevarova, P.A. Kosykh, International Journal for Computation Civil and Structural Engineering 10, 85-92 (2014)

14. G.G. Kashevarova, P.A. Kosykh, Sovremeny tehnologii v stroitelstve. Teoria I praktika 1, 84-94 (2016)

15. K.N. Bogoiavlenskiy, A.K. Grigoriev, Obrabotka metallov davleniyem, 133-138 (1963)

16. I.S. Trishevskiy, V.V. Klepanda, Mekhanicheskiye svoystva gnutykh profiley prokata, 58-61 (1977)

17.I.S. Nemkova, Statisticheskiy analiz svoystv materiala i obosnovaniye raschetnykh soprotivleniy gnutykh profiley dlya stroitelnykh mettalicheskikh konstruktsiy (1984)

18. G.A. Arktikov, V.F. Beliayev, L.I. Gladstein, Promyshlennoie i grazhdanskoie stroitelstvo 5,16-24 (1994)

19. P.A. Kosykh, Bulletin of TGASU 2, 135-143 (2015)

20. Eurocode 3: Design of steel structures. Part 1-3: General rules. Supplementary rules for cold-formed members and sheeting. Ref. No. EN 1993-1-3:2006. - Brussels: European Committee for $\mathrm{n}, 2006$. - $125 \mathrm{p}$. 